\title{
Knowledge, attitude and practice of dental students, interns and practitioners to the use of amalgam in a dental institution of Kathmandu, Nepal
}

\author{
Dixit PB' ${ }^{1 D}$, Dixit S ${ }^{2}$ iD, Dahal $S^{3}$ iD, Poudel P4 ${ }^{4}$, Ghimire S $^{\text {iD }}$, Koirala T
}

${ }^{1}$ Punam Basnet Dixit, Associate Professor, Department of Conservative Dentistry and Endodontics; ${ }^{2}$ Siddharth Dixit, Associate Professor, Department of Prosthodontics; ${ }^{3}$ Sirjana Dahal, Lecturer, Department of Community and Public Health Dentistry; ${ }^{4}$ Prakash Poudel, Lecturer, Department of Orthodontics and Dentofacial Orthopaedics; 'Siddharth Ghimire, Lecturer, Department of Conservative Dentistry and Endodontics; ${ }^{6}$ Tribhuwan Koirala, Dental Officer, Kathmandu Medical College and Teaching Hospital, Duwakot, Nepal.

\begin{abstract}
Background: Dental practitioners of Nepal have been using amalgam for years for restoration, but the concern for mercury related health issues and inventions in metallurgy science have recently led to its decreased use.

Objectives: To assess the knowledge, attitude and practice of students, interns and dentists to the use of dental amalgam in a dental institution of Kathmandu, Nepal.

Methodology: A cross-sectional study was conducted in a dental institution of Kathmandu among 192 Dental students, interns, dental officers and dental specialists selected by census sampling method. Self-administered questionnaire consisting of 16 questions related to amalgam war, its use and safety was used. Data collected were analyzed using Statistical Package for Social Sciences version 20. Frequency and percentage were calculated for each response according to different professional levels.

Results: Most of the respondents including all the dental officers did not use amalgam frequently for restoration (141, $73.44 \%)$. Mercury toxicity was their major concern that restricted amalgam use $(60,31.25 \%)$. Most of them, $(135,70.31 \%)$ agreed on stopping the use of amalgam. They were comfortable to use composite resin as an alternative to amalgam $(185,96.35 \%)$. Majority $(123,64.06 \%)$ considered amalgam to be an unsafe material and were bothered about the environmental issues of mercury in the dental office $(152,79.16 \%)$.

Conclusion: This study concludes that amalgam was less frequently used for restoration due to the increasing concerns of mercury toxicity. Further studies on safety of other materials that can replace amalgam with long term follow up are necessary before they are considered as a definitive alternative for amalgam.
\end{abstract}

Key words: Amalgam; Attitude; Toxicity.

Access this article online

Website: www.jkmc.com.np

DOI: https://doi.org/10.3126/jkmc.v9i1.33542

\section{HOW TO CITE}

Dixit PB, Dixit S, Dahal S, Poudel P, Ghimire S, Koirala T. Knowledge, attitude and practice of dental students, interns and practitioners to the use of amalgam in a dental institution of Kathmandu, Nepal. J Kathmandu Med Coll. 2020;9(1):31-36.

\section{Address for correspondence}

\section{Dr. Punam Basnet Dixit}

Associate Professor, Department of Conservative Dentistry and Endodontics

Kathmandu Medical College Teaching Hospital,

Duwakot, Bhaktapur, Nepal

E-mail: punambdixit@gmail.com

Copyright $\odot 2020$ Journal of Kathmandu Medical College (JKMC)

ISSN: 2019-1785 (Print), 2091-1793 (Online)

cC) (7) (3) This work is licensed under a Creative Commons cC) Attribution-Non Commercial 4.0 International License.

\section{INTRODUCTION}

A malgam has been used in dentistry as direct Arestorative material of posterior teeth for many years ${ }^{1,2}$. It is the most cost-effective restoration ${ }^{3}$ with easy application, and has strength, durability and bacteriostatic effect ${ }^{4}$. However, the use of this material is decreasing these days due to the increasing concerns regarding detrimental health effects, environmental hazards and aesthetics ${ }^{5}$.

Although there are concerns regarding mercury toxicity, most dental institutions hold amalgam as the material of choice for undergraduate students ${ }^{6}$. In a study conducted in Saudi Arabia, the majority of dentists believed amalgam to be safe for dentists and patients. They selected amalgam over other contemporary materials due to its superior longevity ${ }^{7}$. There is a 
broad consensus for continuing a minor component of teaching theoretical aspects including clinical use of dental amalgam for undergraduates ${ }^{8}$.

There is paucity of studies regarding dental undergraduates and practitioners' perception regarding amalgam as a restorative material in Nepal. Therefore, this study was conducted to assess the knowledge, attitude and practice of dental students, interns and practitioners working in Kathmandu Medical College to use amalgam as a restorative material.

\section{METHODOLOGY}

A descriptive cross-sectional study was conducted among 192 dental students, interns, dental officers and specialists working in Kathmandu Medical College and Teaching Hospital, Duwakot from Jan 2019 to June 2020. Ethical approval was obtained from the Institutional Review Committee (IRC) of the same institution before data collection. Census method was used for selecting the study participants including dental students, interns, dental officers and faculties present during study period and informed consent was received from them. BDS third, fourth and final year students who had clinical postings in the Department of Conservative Dentistry and Endodontics were included in the study. Students, graduates and faculties who agreed to participate and were present during the study period were included. Those who had never used amalgam as a filling material were excluded.

A 16-item structured questionnaire was developed based on the published studies on amalgam and pretested among 10 first batch Dental interns. Face and content validity of the questionnaire were checked. The questionnaire consisted of structured questions with closed ended response. Some questions were modified according to the response of the pretested questionnaire after identifying their difficulty in comprehension. Final questionnaire consisted of demographic profile and questions regarding knowledge, attitude and practice towards amalgam use and safety. The self-administered questionnaires were provided to the participants and were collected by the investigators after they were filled.
Data were entered in Microsoft Excel Sheet and analyzed according to different professional level using Statistical Package for Social Sciences version 20. Frequency and percentage were calculated for each response.

\section{RESULTS}

In this survey, 234 individuals were approached for participation and provided with the pre-tested questionnaire. However, the filled questionnaire was obtained from 192 study participants bringing the overall response rate to $82.05 \%$. The demographic profile of the study participants is represented in table 1 . Mean age of the study participants was $25.69 \pm 4.70$ years and most of them were females $(132,68.8 \%)$. Majority of the study population included students $(90,46.9 \%)$ and the minority were faculties $(26,13.5 \%)$.

The participants' responses to various questions regarding use of amalgam and its alternatives are presented in table 2. More than half of the study participants did not use amalgam frequently for restoration $(141,73.44 \%)$ including all the dental officers. At times, 70 (36.46\%) of them used amalgam for larger restorations. However, 80 (41.67\%) never used amalgam at all. Mercury toxicity was the major concern that made them restrict the use of amalgam (60,31.25\%). However, poor aesthetics and patient's desire to use tooth colored restoration was also considered by them. However, more than half of them $(113,58.85 \%)$ disagreed on replacing a good amalgam restoration already present on tooth with composite.

Majority of respondents (135, 70.31\%) agreed on stopping the use of amalgam. They were comfortable to use composite resin as a restorative material as an alternative to amalgam (185, 96.35\%). The responses on amalgam war are presented in table 3 . Most of the participants $(147,76.56 \%)$ were aware of amalgam controversy but $33(17.18 \%)$ were unsure of it. Most of the study participants $(123,64.06 \%)$ considered amalgam to be an unsafe material and were bothered about the environmental issues of mercury in the dental office $(152,79.16 \%)$. However, 32 (16.66\%) were uncertain of amalgam safety.

Table 1: Demographic profile of study participants

\begin{tabular}{lccccc}
\hline Variables & Students & Interns & Dental officers & Dental faculties & Overall \\
Mean age in years (SD) & $23.29(2.93)$ & $24.67(1.22)$ & $26.14(0.99)$ & $34.96(4.76)$ & $25.69(4.70)$ \\
Sex $\mathbf{n}(\%)$ & & & & & \\
Male & $19(21.1)$ & $17(42.5)$ & $9(25)$ & $15(57.7)$ & $60(31.3)$ \\
Female & $71(78.9)$ & $23(57.5)$ & $27(75)$ & $11(42.3)$ & $132(68.8)$ \\
Profession $\mathbf{n ~ ( \% )}$ & $90(46.9)$ & $40(20.8)$ & $36(18.8)$ & $26(13.5)$ & $192(100)$ \\
\hline
\end{tabular}


Table 2: Responses to questions related to use of amalgam and its alternatives $\mathbf{n}(\%)$

\begin{tabular}{|c|c|c|c|c|c|}
\hline Question & Students & Interns & Dental officers & Dental faculties & Total \\
\hline \multicolumn{6}{|c|}{ Do you use dental amalgam for restorations in your clinical practice frequently? } \\
\hline Yes & $37(41.11)$ & $12(30)$ & $0(0)$ & $2(7.70)$ & $51(26.56)$ \\
\hline No & $53(58.89)$ & $28(70)$ & $36(100)$ & $24(92.30)$ & $141(73.44)$ \\
\hline \multicolumn{6}{|l|}{ Have you used dental amalgam for the following? } \\
\hline Simple restorations & $16(17.79)$ & $4(10)$ & $7(19.44)$ & $4(15.38)$ & $31(16.15)$ \\
\hline Large restorations & $29(32.22)$ & $16(40)$ & $11(30.56)$ & $14(53.85)$ & $70(36.46)$ \\
\hline Core material & $2(2.22)$ & $1(2.5)$ & $1(2.78)$ & $0(0)$ & $4(2.08)$ \\
\hline Build up material & $4(4.44)$ & $0(0)$ & $2(5.55)$ & $1(3.84)$ & $7(3.64)$ \\
\hline Don't use at all & $39(43.33)$ & $19(47.5)$ & $15(41.67)$ & $7(26.93)$ & $80(41.67)$ \\
\hline \multicolumn{6}{|c|}{ What are the reasons that restrict you from using dental amalgam? } \\
\hline Aesthetics & $9(13.04)$ & $3(12.5)$ & $4(12.12)$ & $2(14.28)$ & $18(9.37)$ \\
\hline Mercury Toxicity & $30(33.33)$ & $7(17.5)$ & $16(44.44)$ & $7(26.92)$ & $60(31.25)$ \\
\hline Patient's Desire & $20(10.41)$ & $9(22.5)$ & $9(25)$ & $4(15.38)$ & $42(21.87)$ \\
\hline Aesthetics and patient's desire/mercury toxicity & $21(23.33)$ & $16(40)$ & $3(8.33)$ & $12(46.15)$ & $52(27.08)$ \\
\hline Other reasons & $10(11.11)$ & $5(12.5)$ & $4(11.11)$ & $1(3.85)$ & $20(10.42)$ \\
\hline \multicolumn{6}{|c|}{ Do you agree on replacing good amalgam restoration with composite resin? } \\
\hline Agree & $46(51.11)$ & $14(35)$ & $12(33.33)$ & $7(26.92)$ & $79(41.14)$ \\
\hline Disagree & $44(48.88)$ & $26(65)$ & $24(66.66)$ & $19(73.07)$ & $113(58.85)$ \\
\hline \multicolumn{6}{|c|}{ If a patient had defective amalgam restoration, what would you prefer changing it to? } \\
\hline Amalgam & $9(10)$ & $12(30)$ & $0(0)$ & $6(23.07)$ & $27(14.06)$ \\
\hline Composite & $59(65.56)$ & $20(50)$ & $34(94.44)$ & $13(50)$ & $126(65.62)$ \\
\hline Any of the above & $22(24.44)$ & $8(20)$ & $2(5.55)$ & $7(26.92)$ & $39(20.31)$ \\
\hline \multicolumn{6}{|c|}{ Do you agree on stopping the use of amalgam as a final restoration? } \\
\hline Agree & $66(73.33)$ & $26(65)$ & $30(83.33)$ & $13(50)$ & $135(70.31)$ \\
\hline Disagree & $24(26.66)$ & $14(35)$ & $6(16.66)$ & $13(50)$ & $57(29.68)$ \\
\hline \multicolumn{6}{|l|}{ Would you recommend an alternative to amalgam? } \\
\hline Yes & $71(78.888)$ & $36(90)$ & $34(94.44)$ & $16(61.53)$ & $157(81.77)$ \\
\hline No & $10(11.11)$ & $2(5)$ & $2(5.55)$ & $5(19.23)$ & $19(9.89)$ \\
\hline Uncertain & $9(10)$ & $2(5)$ & $0(0)$ & $5(19.23)$ & $16(8.33)$ \\
\hline \multicolumn{6}{|c|}{ Which of the following amalgam alternatives are you comfortable working with? } \\
\hline Resin composite & $84(93.33)$ & $40(100)$ & $36(100)$ & $25(96.15)$ & $185(96.35)$ \\
\hline Glass lonomer Cement & $5(5.55)$ & $0(0)$ & $0(0)$ & $0(0)$ & $5(2.60)$ \\
\hline Others (Cast gold restoration/ceramic restoration) & $1(1.11)$ & $0(0)$ & $0(0)$ & $1(3.84)$ & $2(1.04)$ \\
\hline
\end{tabular}

Table 3: Responses regarding amalgam war $\mathbf{n}(\%)$

\begin{tabular}{|c|c|c|c|c|c|}
\hline \multicolumn{6}{|c|}{ Are you aware of amalgam controversy? } \\
\hline Yes & $61(67.67)$ & $34(85)$ & $30(83.33)$ & $22(61.11)$ & $147(76.56)$ \\
\hline No & $9(10)$ & $0(0)$ & $0(0)$ & $3(11.53)$ & $12(6.25)$ \\
\hline Uncertain & $20(22.22)$ & $6(15)$ & $6(16.66)$ & $1(3.84)$ & $33(17.18)$ \\
\hline \multicolumn{6}{|c|}{ What was your source of awareness? } \\
\hline Patient enquiries & $1(1.6)$ & $0(0)$ & $0(0)$ & $1(4.5)$ & $2(1.4)$ \\
\hline Undergraduate education & $35(57.4)$ & $22(64.7)$ & $24(80.0)$ & $5(22.7)$ & $86(58.5)$ \\
\hline Conferences & $4(6.6)$ & $1(2.9)$ & $3(10.0)$ & $6(27.3)$ & $14(9.5)$ \\
\hline Colleagues & $0(0)$ & $2(5.9)$ & $0(0)$ & $1(4.5)$ & $3(2.0)$ \\
\hline Continuing dental education & $21(34.4)$ & $9(26.5)$ & $3(10.0)$ & $9(40.9)$ & $42(28.6)$ \\
\hline
\end{tabular}


Table 3 cont ...

What is your opinion about amalgam safety?

\begin{tabular}{|c|c|c|c|c|c|}
\hline Safe & $19(21.11)$ & $4(1)$ & $2(5.55)$ & $12(46.15)$ & 37 (19.27) \\
\hline Unsafe & $55(61.11)$ & $28(70)$ & 30 (83.33) & $10(38.46)$ & $123(64.06)$ \\
\hline Uncertain & 16 (17.77) & $8(29)$ & $4(11.11)$ & $4(15.38)$ & $32(16.66)$ \\
\hline \multicolumn{6}{|c|}{ What is your patient's opinion about amalgam safety? } \\
\hline Safe & $6(6.66)$ & $6(15)$ & $2(5.55)$ & $3(11.53)$ & $17(8.85)$ \\
\hline Unsafe & $11(12.22)$ & $4(1)$ & $8(22.22)$ & $1(3.84)$ & $24(12.5)$ \\
\hline Uncertain & $73(81.11)$ & $30(75)$ & $26(72.22)$ & $22(84.61)$ & $151(78.64)$ \\
\hline \multicolumn{6}{|c|}{ How do you respond to a patient's request to have his/her amalgam removed based on amalgam war? } \\
\hline Agree & $47(52.22)$ & $18(45)$ & $17(47.22)$ & $8(30.76)$ & $90(46.88)$ \\
\hline Disagree and explain & $43(47.78)$ & $22(55)$ & $19(52.77)$ & $18(69.23)$ & $102(53.12)$ \\
\hline \multicolumn{6}{|c|}{ What is your opinion about the controversy on amalgam ban? } \\
\hline Ban & $43(47.77)$ & $18(45)$ & $26(72.22)$ & $9(34.61)$ & $96(50)$ \\
\hline Don't ban & $27(30)$ & $10(25)$ & $2(5.55)$ & $12(46.15)$ & $51(26.56)$ \\
\hline Uncertain & $20(22.22)$ & $12(30)$ & $8(22.22)$ & $5(19.23)$ & $45(23.44)$ \\
\hline \multicolumn{6}{|c|}{ Is dental amalgam an occupational risk factor at your workplace? } \\
\hline Yes & $75(83.33)$ & $28(70)$ & $30(83.33)$ & $14(53.84)$ & $147(76.56)$ \\
\hline No & $15(16.66)$ & $12(30)$ & $6(16.66)$ & $12(46.15)$ & $45(23.43)$ \\
\hline \multicolumn{6}{|c|}{ Are you bothered about the environmental issues of mercury in the dental office? } \\
\hline Yes & $72(80)$ & $34(85)$ & $28(77.77)$ & $18(69.23)$ & $152(79.16)$ \\
\hline No & $7(7.77)$ & $2(5)$ & $2(5.55)$ & $5(19.23)$ & $16(8.33)$ \\
\hline Not sure & $11(12.22)$ & $4(10)$ & $6(16.66)$ & $3(11.53)$ & $24(12.5)$ \\
\hline
\end{tabular}

\section{DISCUSSION}

There is a continuous debate since years on use of dental amalgam, degree of mercury release and its potential health effects although many reports on scientific evidence demonstrate amalgam to be a safe and effective restorative material ${ }^{9}$. There is also a larger concern for mercury toxicity during amalgam restoration in children due to their developmental immaturity ${ }^{10}$. However, there are several big national and international dental organizations stating that mercury fillings are stable ${ }^{11}$. This study was conducted to assess the knowledge, attitude and practice of students, interns and dentists to the use of dental amalgam in a dental institution of Kathmandu, Nepal.

In the present study, a larger number of study population did not use amalgam frequently for restoration (141, 73.44\%), including all the dental officers. Among different groups of study participants, amalgam was used mostly by students $(37,41.11 \%)$. Students frequently used this material because they have specified a quota for amalgam restoration to be fulfilled in their BDS curriculum under Kathmandu University. Majority of participants
$(80,41.67 \%)$ did not use amalgam at all. The amalgam users preferred this material for large restorations (70, $36.46 \%$ ) as conventional cavity preparation can be done in a larger cavity without cutting excess tooth material. Amalgam can provide satisfactory performance even for larger restorations and can be retained for a longer duration of time without any mechanical failure ${ }^{12}$.

Mercury toxicity was the major concern that made the study participants restrict the use of amalgam (60, $31.25 \%)$. Mercury toxicity may result from the inhalation of mercury vapors. Therefore, amalgam containing mercury should be handled with extreme care. The amalgam wastes should not be incinerated or autoclaved because mercury volatilized forming mercury vapors and entering the atmosphere, risking mercury toxicity ${ }^{13}$. Improper handling and disposal of amalgam may lead to substantial threat of the hazardous conditions ${ }^{14}$. Therefore, all the individuals handling dental amalgam should be informed regarding the potential hazards of mercury vapour and trained for good mercury hygiene practices ${ }^{15}$. The risks of adverse health effects in the dental office can be minimized by following the recommended 
mercury hygiene protocols ${ }^{16}$. Poor aesthetics and patient's desire to use tooth colored restoration were also considered by the study participants. More than half of them $(147,76.56 \%)$ including most of the students $(75,83.33 \%)$ and dental officers $(30,83.33 \%)$ considered amalgam as an occupational risk factor at their workplace and agreed to replace amalgam with other restorative materials $(113,58.85 \%)$.

There are many factors influencing the choice in posterior restoration material, like funding, time expenditure, experience, clinical outcomes and pre-existing attitudes. A study done by Gilmour, Evans and Addy highlighted the fact that placing composite would take longer time in posterior teeth and are more expensive than amalgam ${ }^{17}$. In contrast, most of the study participants in this study would prefer changing a defective amalgam restoration to composite $(126,65.62 \%)$. More than half of them $(135,70.31 \%)$ agreed on stopping the use of amalgam as a final restoration. They were comfortable to use composite resin as a restorative material as an alternative to amalgam $(185,96.35 \%)$.

Majority of the study participants in the current study were aware of amalgam controversy (147, 76.56\%). Most of them had learned about amalgam war in their undergraduate education $(86,58.5 \%)$ which is similar to the source of awareness reported in a study done by Udoye and Aguwa where $82.9 \%$ had gained knowledge about it through education in undergraduate program ${ }^{18}$.

In this study, most of the study participants (123, 64.06\%) considered amalgam to be an unsafe material. Only a few participants $(37,19.27 \%)$ thought this material to be safe and 32 (16.66\%) were uncertain about it. This finding is similar to a study done by Pooja and Delphinepriscilla Antony, where most of the general dental practitioners responded amalgam to be unsafe ${ }^{19}$. Among the participants responding to amalgam as a safe material, majority $(12,46.15 \%)$ were dental specialists, followed by dental students $(19,21.11 \%)$, dental officers $(2$, $5.55 \%)$ and interns (4, 1\%). However, in a study done by Natarajan $\mathrm{K}$ and Ranjan M, 13\% of third years, $7 \%$ of final years and $9 \%$ of interns considered amalgam as a safe material and $4 \%, 10 \%$ and $5 \%$ were uncertain of amalgam safety ${ }^{16}$. When asked about their patients' opinion, patients of most of the study participants' from all four groups were uncertain about amalgam safety. This result is in contrast to a study done by Udoye and Aguwa where more patients who were seen by general practitioners (85.1\%) than specialists (34.8\%) agreed that amalgam is safe, while more of the patients seen by specialists (39.1\%) than general practitioners (6.4\%) were uncertain about amalgam safety ${ }^{18}$.

The environmental effects of mercury component in dental amalgam have been highlighted lately. Environmental authorities have provided laws and recommendations due to which there is increasing installation of amalgam separators in dental units during the past decade ${ }^{20}$. However, in dental set ups of a developing country like Nepal, separators are barely found connected. In the present study, majority of respondents $(152,79.16 \%)$ were bothered about the environmental issues of mercury in the dental office and would recommend an alternative to amalgam (157, $81.77 \%$ ). Their concern would mostly be due to improper disposal of amalgam that affects the surroundings. A published study has also shown that practice of waste segregation and amalgam disposal in dental practice is poor $^{21}$.

Half of the study participants $(96,50 \%)$ including most of the dental officers $(26,72.22 \%)$ were in favor of banning amalgam use in dentistry. However, when their patients requested to have his/her amalgam removed due to amalgam war, most of them $(102,53.12 \%)$ disagreed to do so and explained to them that amalgam may be more hazardous during removal than in placed condition.

This study has some limitations. The study was conducted in a single dental institution only and the sample was selected by convenience sampling method due to which the responses obtained cannot be generalized to the opinion of all the dental faculties, dental officers, interns and students of Nepal. The comparative assessment could not be computed to statistical analysis and interpreted because of uneven distribution of study participants in different groups.

\section{CONCLUSION}

This study concludes that amalgam was less frequently used for restoration due to the increasing concerns of mercury toxicity. Composite resin was preferred as an alternative to amalgam. However, participants did not want to replace the tooth already filled with good amalgam restoration to composite. Further studies on safety of other materials that can replace amalgam with long term follow up are necessary before they are considered as a definitive alternative for amalgam.

\footnotetext{
Conflict of interest: None

Source(s) of support: None
} 


\section{REFERENCES}

1. Pink FE, Minden NJ, Simmonds S. Decisions of Practitioners regarding Placement of Amalgam and Composite Restorations in General Practice Settings. Oper Dent. 1994;19:127-32. [PubMed]

2. Berry TG, Summit JB, Chung AK, Osborne JW. Amalgam at the new millennium. J Am Dent Assoc. 1998;129:1547-56. [DOI]

3. Osborne JW. Amalgam: Dead or alive? Dent Update 2006;33:94-8. [PubMed | DOI]

4. Rathore $M$, Singh A, Pant VA. The dental amalgam toxicity fear: a myth or actuality. Toxicology international. 2012 May;19 (2):81. [PubMed | DOI]

5. Dunne SM, Grainsford ID, Wilson NH. Current Materials and Techniques for Direct Restorations in Posterior Teeth. Part 1: Silver Amalgam. Int Dent J. 1997;47:123-36. [PubMed]

6. Shenoy A. Is it the end of the road for dental amalgam? A critical review. J Conserv Dent 2008;11:99-107. [PubMed | DOI]

7. Al-Nahedh, HN., El-Hejazi, AA. andHabib SR. Knowledge and Attitude of Dentists and Patients Toward Use and Health Safety of Dental Amalgam in Saudi Arabia. Eur J Dent. 2020 Mar;14 (2):233-238. [PubMed |DOI]

8. Alexander G, Hopcraft MS, Tyas MJ, Wong R. Dentists' restorative decision-making and implications for an 'amalgamless' profession. Part 5: knowledge factors. Aust Dent J. 2017;62:440-452. [PubMed | DOI]

9. American Dental Association Council on Scientific Affairs. Dental amalgam: Update on safety concerns. J Am Dent Assoc. 1998 Apr 1;129(4):494-503. [PubMed | DOI]

10. Bellinger DC, Trachtenberg F, Barregard L, Tavares $M$, Cernichiari E, Daniel D et al. Neuropsychological and renal effects of dental amalgam in children: a randomized clinical trial. J Am Dent Assoc. 2006 Apr 19;295(15):1775-83. [PubMed | DOI]

11. Bengtsson UG, Hylander LD. Increased mercury emissions from modern dental amalgams. Biometals. 2017 Apr 1;30(2):277-83. [PubMed | DOI]
12. Bharti R, Wadhwani KK, Tikku AP, Chandra A. Dental amalgam: An update. J Conserv Dent: JCD. 2010 Oct;13(4):204-8. [PubMed | DOI]

13. Bharadwaj $S$, Bharadwaj A, Kalra T. Knowledge and practices regarding mercury hygiene and amalgam waste disposal: A survey among general dental practitioners. Indian J Dent Sci. 2017;9:30-3. [Full Text]

14. Pawar PA, Patil TS. Knowledge, practice and attitude of dental care waste management among private dental practitioners in Latur city. Int Dent J Students Res. 2017 Oct;5:80-4. [Full Text]

15. Riswana NA. Knowledge and Attitude in Regards to Dental Care Waste Management amongst Dental Students-Questionnaire Study. J Pharm Sci Res. 2016 Sep 1;8(9):1070. [Full Text]

16. Natarajan K, Ranjan M. Knowledge, Attitude and Practice on Dental Amalgam Restoration among Dental Students. J Pharm Res Int. 2020 Aug 26:3948. [Full Text | DOI]

17. Gilmour AS, Evans P, Addy LD. Attitudes of general dental practitioners in the UK to the use of composite materials in posterior teeth. Br Dent J. 2007 Jun;202(12):E32-. [PubMed | Full Text | DOI]

18. Udoye C, Aguwa E. Amalgam safety and dentists' attitude: a survey among a subpopulation of Nigerian dentists. Oper Dent. 2008 Jul;33(4):467-71. [PubMed | DOI]

19. Pooja S, Delphinepriscilla Antony S. Dentists attitude towards amalgam restoration and its safety measures-KAP survey. Drug Invent Today. 2019 Jan 15;12:9-12. [Full Text]

20. Ylinen K, Löfroth $G$. Nordic dentists' knowledge and attitudes on dental amalgam from health and environmental perspectives. ActaOdontologicaScandinavica. 2002 Jan 1;60(5):315-20. [PubMed | Full Text | DOI]

21. Mohamed Ahmed AA, MohieldinAwooda E, Elbeshir El. Dentists Knowledge, Attitude and Practice towards Dental Waste Management in Dental Clinics- Khartoum Locality. Int J Latest Res Sci Tech. 2014;3;4:93-6. [Full Text] 